\title{
OPHIOBOLUS GRAMINIS SACC. TODETTU MAASSAMME KEVÄTVEHNÄSSÄ
}

\author{
KATRI IKÄHEIMO \\ Kasvitautien tutkimuslaitos, Tikkurila
}

Saapunut 27. 3. 1959.

Kasvitautien tutkimuslaitoksen taholta todettiin, että syksyllä 1958 Uudellamaalla esiintyi eräiden tilojen kevätvehnäviljelyksillä huomattavan runsaasti $\mathrm{k}$ a h u tä h kä i s y y t tä. Pelloilta kerätyissä kevätvehnänäytteissä oli korsien tyvessä runsaasti Cercosporella herpotrichoides Fron-sienen aiheuttamia tyvilaikkuja ja Fusarium sp.-sieniä, jotka HÅRDH (2) on todennut maassamme kahutähkäisyyden aiheuttajiksi. Lisäksi eräissä korsissa oli tyvivioitusta, joka ei näyttänyt näiden sienien aiheuttamalta. Tällaisten kasvien juuret, mesokotyyli ja korren tyvi olivat tummuneet melkein mustiksi. Juuret katkeilivat helposti ja korren tyvessä lehtitupen sekä korren välissä oli tummaa, tiheätä sienirihmastoa. Korren sisässä ei sen sijaan yleensä ollut sienirihmastoa havaittavissa. Symptomit viittasivat Ophiobolus graminis Sacc.:n aiheuttamaan viljan mustatyvitautiin. Sienen eristämistä varten pidettiin korsia kosteudessa lasikuvun alla. 10-14 vrk. kuluttua niiden tyveen muodostui kotelopulloja, jotka todettiin $O$. graminiseksi. Kotelopullot olivat soikeanpyöreitä, pitkäkaulaisia, keskim. $550 \times 350 \mu$ kokoisia (kuva 1). Itiökotelot olivat keskim. $101.3 \times 12.2 \mu$ suuruisia (vaihtelut $72-120 \times 9-15 \mu$ ). Koteloitiöt olivat kooltaan keskim. $86.9 \times 4.2 \mu$ (vaihtelut $60-111 \times 3-6 \mu$ ), muodoltaan pitkiä, kapeita, pyöreäpäisiä ja $2-8$-väliseinäisiä. Nämä koot vastaavat kirjallisuudessa $O$. graminisesta esitettyjä tietoja $(3,5,7,8)$.

Suomessa on REUTER (6) selostanut v. 1910 Hausjärvellä Etelä-Hämeessä syysrukiissa huomattua tautia, jonka hän päättelee Ophiobolus-sienten aiheuttamaksi. Sen aikaisten kirjallisuustietojen perusteella REUTER mainitsee $O$. graminis Sacc.- ja O. herpotrichus (Fr.) Sacc.-sienet Ophiobolus-taudin aiheuttajaksi.

Kotelopulloista eristettyjä koteloitiöitä kasvatettiin erilaisilla ravintoalustoilla. Sienen kasvu oli huonelämpötilassa rehevintä $5 \%$ :lla kaura-agarilla ja $2 \%$ :lla mallasuuteagarilla. Sieni muodosti ravintoalustoille harmaata rihmastoa, jossa erottuivat tummat, paksuhkot, inokulointikohdissa ympäristöönsä säteettäisesti kasvavat hyyfit ja joista haarautui runsaasti ohuita, värittömiä sienirihmoja. 


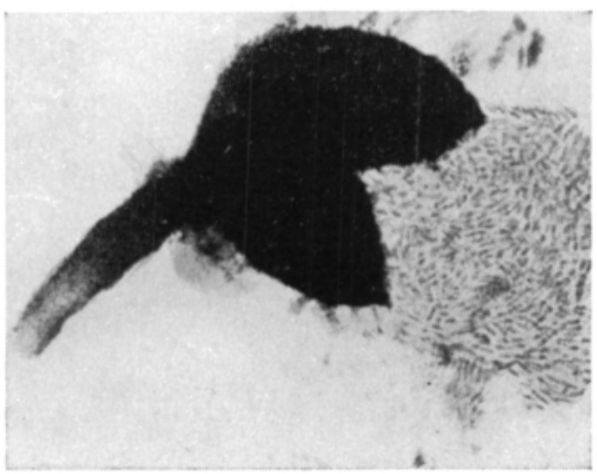

Kuva 1. Ophiobolus graminisen kotelopullo, josta purkautuu itiökoteloita. Suurennus n. $\times 100$.

Viimeksi mainituissa ei ollut selvästi todettavissa väliseiniä, kun taasen tummat, paksuhkot sienirihmat olivat aina väliseinällisiä (vrt. 1, 2). Sieni ei muodostanut ravintoalustoille kotelopulloja.

Koteloitiöillä tehtiin kaksi infektiokoetta, toinen Apu- ja toinen Timantti IIkevätvehnällä. Inokulointi tapahtui RUSSELLin (7) selostaman menetelmän mukaan. Jyviä idätettiin pari päivää, jolloin niihin muodostui itu ja juuret. Näin saadut oraat istutettiin astioihin desinfioituun multaan ja jokaisen oraan viereen pantiin puhdasviljelmistä otettuja agaripalasia, joissa oli O. graminis-kasvustoa. Koekasvit pidettiin kasvihuoneessa. Ensimmäiset infektioitumisen merkit havaittiin 2 viikon kuluttua inokuloinnista; saastuneet kasvit olivat silloin nuutuneita. Vähitellen ne alkoivat kasvien tyven mustuessa (kuva 2) kellastua ja kuihtua. Kuolleiden kasvien kosteina pidettyihin tyviosiin muodostui myöhemmin runsaasti kotelo-

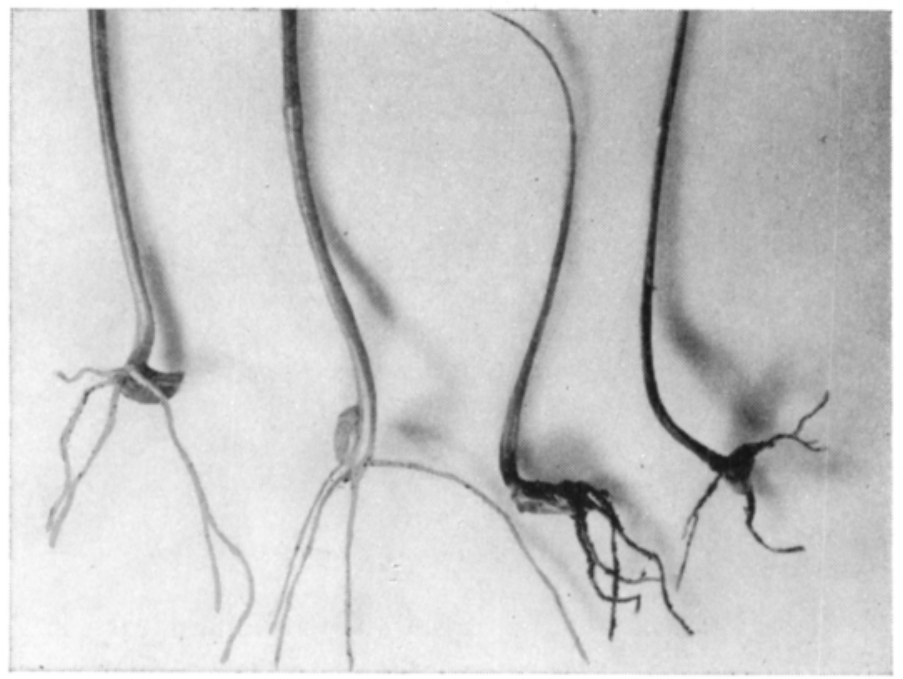

Kuva 2. Oikealla kaksi Ophiobolus graminisella saastutettua kevätvehnäyksilöä; vasemmalla kaksi saman kokeen inokuloimatonta kasvia. 
pulloja ja koteloitiöitä. Viimeksi mainitut olivat myöhemmin 50 vrk. kuluttua inokuloinnista keskim. $72.6 \times 3.3 \mu$ suuruisia (vaihtelut $60-81 \times 3-4.5 \mu$ ). Itiöiden verraten pieni koko johtunee niiden nuoruudesta. Myös KIRBY (4) totesi O. graminisen koteloitiöiden olevan kasvun alussa n. $10-20 \mu$ pienempiä kuin myöhemmin.

Apu-vehnällä suoritetussa kokeessa oli 40 inokuloidusta kasvista 34 vrk. kuluttua kokeen alkamisesta kuollut 39. Timanttivehnällä suoritetussa kokeessa saastuivat aikana 10.1.-10. 2.1959 kaikki 57 inokuloitua kasvia. Tämän lajikkeen kontrollikasvien oraiden keskimääräinen pituus oli keskim. $38.4 \mathrm{~cm}$ ja juurien pituus keskim. $12.0 \mathrm{~cm}$; vastaavasti infektoituneissa kasveissa oraiden pituus oli $19.4 \mathrm{~cm}$ ja juurien pituus $3.7 \mathrm{~cm}$.

Alla olevassa asetelmassa on esitetty $O$. graminisen esiintyminen 4-6. 9. 1958 kerätyissä kevätvehnänäytteissä. Sieni todettiin näytteistä mikroskooppisesti kotelopullojen ja itiöiden perusteella. Koteloitiöiden muodostumista edistettiin pitämällä korsien tyvet kosteina muovipusseissa.

\begin{tabular}{|c|c|c|}
\hline $\begin{array}{l}\text { Näytteen ottopaikka } \\
\text { Location of samples }\end{array}$ & $\begin{array}{c}\text { Tarkastet- } \\
\text { tuja kasveja } \\
\text { yhteensä } \\
\text { kpl. } \\
\text { Number of } \\
\text { plants } \\
\text { inspected }\end{array}$ & $\begin{array}{l}\text { Kasveja, } \\
\text { joissa } O . \\
\text { graminis } \\
\text { kpl } \\
\text { Number of } \\
\text { plants with } \\
\text { O. graminis }\end{array}$ \\
\hline
\end{tabular}

Ab. Inkoo, Västankvarn, Apu-vehnä, lakoutunut Apu spring wheat, lodged

, Kalkulla, Svenno-vehnä, kahutähkäinen Svenno spring wheat, with shrivelled heads heads

N. Porvoon mlk. Kullågård, Svenno-vehnä, kahutähkäinen Svenno spring wheat, with shrivelled heads

- Kullågård, Svenno-vehnä, kahutähkäinen Svenno spring wheat, with shrivelled heads

- Kullågård, Timantti-vehnä, kahutähkäinen Diamond spring wheat, with shrivelled heads

* Dalgård, kevätvehnä spring wheat
50

80

50

50

50

7

8

30

50

\section{Yhteenveto}

Syksyllä 1958 Uudellamaalla kerätyistä kevätvehnänäytteistä, jotka us:immat kahutähkäisiä, määritettiin tyvitaudin aiheuttajaksi Ophiobolus graminis Sacc. Puhdasviljelyllä sienellä infektoitiin kevätvehnä, jolloin se sairastui tyypilliseen O. graminisen aiheuttamaan viljan mustatyvitautiin. 


\section{KIRJALLISUUTTA}

(1) Davis, R. J. 1925: Studies on Ophiobolus graminis Sacc. and the take-all disease of wheat. J. Agric. Res. 31: 801-840.

(2) Нᄉ̊RDH, J. E. 1953: Kevätvehnän kahutähkäisyydestä sekä sen syistä Suomessa. Referate: On the shrivelheads of spring wheat and their causes in Finland. Valt. maat. koet. julk. 140: $1-153$.

(3) Jones, S. G. 1926: The development of the perithecium of Ophioholus graminis Sacc. Ann. Bot. 40: $606-629$.

(4) Kirby, R. S. 1922: The take-all disease of cereals and grasses. Phytopath. 12: 66-68.

(5) Nilsson-EHLE, H. 1902: Stråknäckning hos höstvete, förorsakad of svampen Leptosphaeria herpotrichoides de Not.; och dess förhållande hos olika sorter. Något om en annan å höstvete förekommande svamp (Ophiobolus graminis Sacc.). Sv. Utsädesför. tidsskr., Heft $\mathbf{4}$, p. $1-27$.

(6) Reuter, Enzio 1912. 16. kertomus tuhohyönteisten esiintymisestä Suomessa vuonna 1910. Maanvilj. hall. tied. 84: $1-17$.

(7) Russell, R. C. 1934: Studies in cereal diseases X. Studies of take-all and its causal organism, Ophiobolus graminis Sacc. Canad. Dept. Agric. Bull. 170: 1-64.

(8) Saccardo, P. A. 1883: Sylloge Fungorum 9: 349.

\section{S U M M A R Y :}

\section{THE DETERMINATION OF OPHIOBOLUS GRAMINIS SACC. ON SPRING WHEAT IN FINLAND}

\section{KATRI IKÄHEIMO}

Department of Plant Pathology, Agriculture Research Centre, Tikkurila.

From samples of spring wheat with shrivelled heads collected in the autumn 1958 from Uusimaa (cf. Table on p. 182), a province in South Finland, the presence of Ophiobolus graminis Sacc. has been determined. With pure cultures of this fungus inoculations where made on young spring wheat plants, resulting symptoms of the take-all disease. 